\title{
Mechanism of the Affinity-Enhancing Effect of Isatin on Human Ferrochelatase and Adrenodoxin Reductase Complex Formation: Implication for Protein Interactome Regulation
}

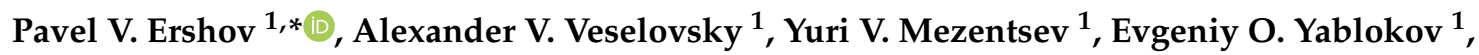 \\ Leonid A. Kaluzhskiy ${ }^{1}{ }^{(\mathbb{D}}$, Anastasiya M. Tumilovich ${ }^{2}$, Anton A. Kavaleuski ${ }^{2}$, Andrei A. Gilep ${ }^{2}$, \\ Taisiya V. Moskovkina ${ }^{3}$, Alexei E. Medvedev ${ }^{1}$ and Alexis S. Ivanov ${ }^{1}$ \\ 1 Institute of Biomedical Chemistry, 10 Building 8, Pogodinskaya Street, 140006 Moscow, Russia; \\ veselov@ibmh.msk.su (A.V.V.); yuri.mezentsev@ibmc.msk.ru (Y.V.M.); \\ evgeniy.yablokov@ibmc.msk.ru (E.O.Y.); leonid.kaluzhskiy@ibmc.msk.ru (L.A.K.); \\ alexei.medvedev@ibmc.msk.ru (A.E.M.); alexei.ivanov@ibmc.msk.ru (A.S.I.) \\ 2 Institute of Bioorganic Chemistry NASB, 5 Building 2, V.F. Kuprevich Street, 220141 Minsk, Belarus; \\ tumilovicham@iboch.by (A.M.T.); bio.kovalevs@iboch.by (A.A.K.); agilep@iboch.by (A.A.G.) \\ 3 Far East Federal University, FEFU Campus, 10 Ajax Bay, Russky Island, 690922 Vladivostok, Russia; \\ moskovkina.tv@dvfu.ru \\ * Correspondence: pavel.ershov@ibmc.msk.ru; Tel.: +7-499-246-71-15
}

Received: 21 September 2020; Accepted: 12 October 2020; Published: 14 October 2020

\begin{abstract}
Isatin (indole-2, 3-dione) is a non-peptide endogenous bioregulator exhibiting a wide spectrum of biological activity, realized in the cell via interactions with numerous isatin-binding proteins, their complexes, and (sub) interactomes. There is increasing evidence that isatin may be involved in the regulation of complex formations by modulating the affinity of the interacting protein partners. Recently, using Surface Plasmon Resonance (SPR) analysis, we have found that isatin in a concentration dependent manner increased interaction between two human mitochondrial proteins, ferrochelatase (FECH), and adrenodoxine reductase (ADR). In this study, we have investigated the affinity-enhancing effect of isatin on the FECH/ADR interaction. The SPR analysis has shown that FECH forms not only homodimers, but also FECH/ADR heterodimers. The affinity-enhancing effect of isatin on the FECH/ADR interaction was highly specific and was not reproduced by structural analogues of isatin. Bioinformatic analysis performed using three dimensional (3D) models of the interacting proteins and in silico molecular docking revealed the most probable mechanism involving FECH/isatin/ADR ternary complex formation. In this complex, isatin is targeted to the interface of interacting FECH and ADR monomers, forming hydrogen bonds with both FECH and ADR. This is a new regulatory mechanism by which isatin can modulate protein-protein interactions (PPI).
\end{abstract}

Keywords: ferrochelatase; adrenodoxin reductase; isatin; in silico; affinity; complex formation; heterodimerization; surface plasmon resonance

\section{Introduction}

Isatin (indole-2,3-dione) is an endogenous oxidized indole exhibiting a certain spectrum of biological and pharmacological activities, including regulation of gene expression, neuroprotection, antitumor action, etc. (for review see [1]). This compound has been found in various tissues and biological fluids of mammals, where its concentration varies from $0.1 \mu \mathrm{M}$ to $10 \mu \mathrm{M}$, and in the case of its administration in vivo, isatin concentration in certain organs (e.g., the brain) can reach 50-100 $\mu \mathrm{M}[1,2]$. 
These numerous biological and/or pharmacological effects are obviously mediated by isatin interaction with many isatin-binding proteins, identified during proteomic profiling of brain preparations of mice and rats [3-5]. However, besides direct action of isatin on its particular targets, characterized by classical binding constants and altered biological functioning of individual proteins [6,7] it can also act as a bidirectional regulator of protein-protein interactions (PPI) increasing or decreasing affinity of interacting protein partners $[1,8]$. This novel regulatory role of isatin has been originally demonstrated by us for the interaction of two pairs of proteins: (1) ferrochelatase (FECH) and adrenodoxin reductase (ADR) [8], (2) thromboxane synthase (TBXAS1) and cytochrome P450 2E1 (CYP2E1) [9]. It was particularly interesting that individual proteins of each investigated pair of the interacting proteins demonstrated low (if any) isatin binding capacity, but the addition of isatin caused a several-fold increase in the affinity of their interaction $[8,9]$.

Our previous SPR study showed that a pharmacologically relevant concertation of isatin $(100 \mu \mathrm{M})$ significantly increased affinity of the FECH/ADR complex: the $K_{d}$ value decreased from $13 \mu \mathrm{M}$ to $2 \mu \mathrm{M}$ [8]. These isatin-induced changes in $\Delta \mathrm{K}_{\mathrm{d}}$ included both an increase in the FECH/ADR association rate (the $\mathrm{k}_{\text {on }}$ value demonstrated a four-fold increase) and a less than 2-fold decrease in the dissociation rate constant $\left(\mathrm{k}_{\text {off }}\right)$ [8]. At a higher pharmacological concentration of isatin $(270 \mu \mathrm{M})$ this effect became even more pronounced (the change in the $K_{d}$ value was more than 15 times). We also found that isatin did not interact with each individual protein (FECH, ADR) immobilized on the optical chip. However, isatin had no effect on other interactions of FECH with cytochrome b5 and SMAD4 thus indicating specificity of its effect on the FECH/ADR interaction [8].

In this study, using a surface plasmon resonance (SPR) based biosensor we have investigated the specificity and molecular mechanism responsible for the affinity-enhancing effect of isatin on the interaction of FECH and ADR. Since FECH can exist in monomeric and dimeric forms $[10,11]$, we have initially investigated which complexes (dimeric or trimeric) $\mathrm{FECH}$ formed during interaction with ADR, and other tested proteins (cytochrome $b_{5}$ type B (CYB5B) and SMAD family member 4 (SMAD4)) [12-14]. Experiments have shown that CYB5B and SMAD4 can interact with both the monomeric and dimeric forms of $\mathrm{FECH}$, with the formation of heterodimeric and heterotrimeric complexes, respectively. At the same time, ADR interacted only with the monomeric form of FECH (with formation of heterodimers). Individual proteins, FECH and ADR, immobilized on the optical chip, did not interact with isatin and its several derivatives. The effect of isatin on the FECH/ADR complex formation was specific, as several isatin analogues tested had no influence on the complex formation. Using computer-aided molecular modeling, the hypotheses of the most probable structures of the FECH/isatin/ADR ternary complexes were constructed. Their comparison with experimental data made it possible to choose the most probable model of such ternary complex. This model reasonably explained the affinity-enhancing effect of isatin on the pair of interacting proteins tested.

\section{Results}

\subsection{Interaction of FECH with $A D R$}

Since FECH can exist both in monomeric and in dimeric forms [10,11], we have performed a comparative SPR analysis of the interaction of ADR with FECH monomers and dimers, immobilized on the optical chip. In accordance with our previous study [8] immobilized FECH monomers interacted in the concentration-dependent manner with added ADR (Figure 1A). In another experiment FECH solutions were injected to verify the ability of immobilized FECH monomers to participate in homodimerization (Figure 2). We also carried out sequential injections of FECH and ADR protein solutions through all four biosensor channels ("empty channel" Fc1 (control 1); channel Fc2 with FECH monomers; channel Fc3 with FECH monomers treated with NHS/EDC mixture (control 2); channel Fc4 with FECH dimers treated with NHS/EDC mixture). 

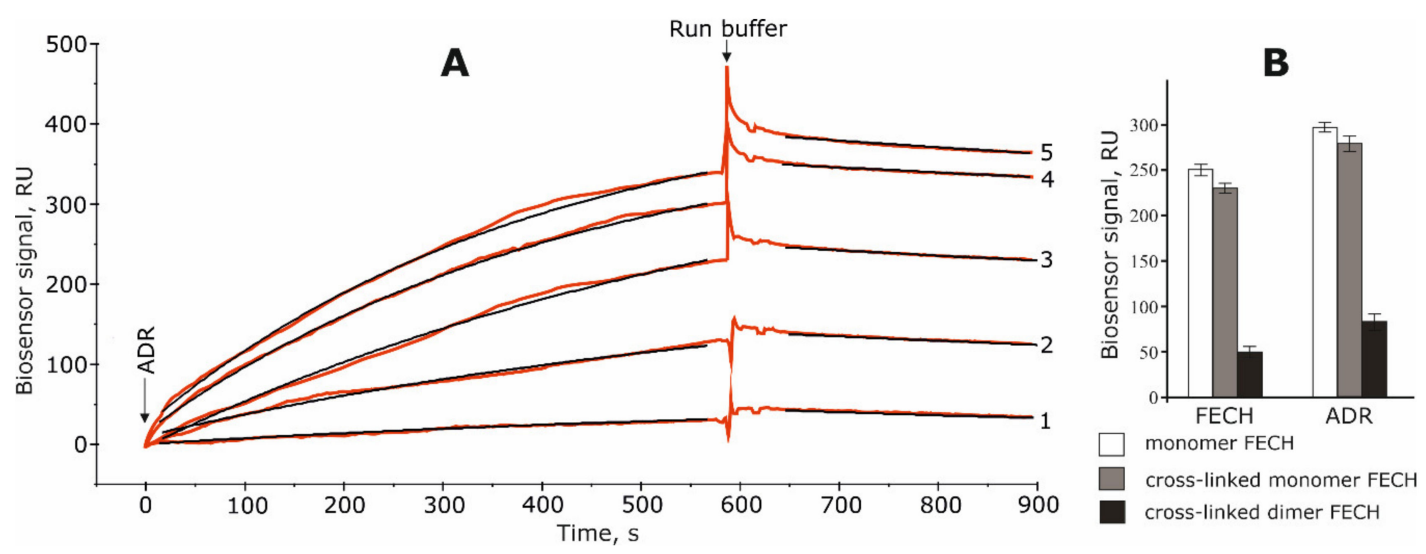

Figure 1. (A) Typical surface plasmon resonance (SPR) binding between immobilized ferrochelatase monomer on the optical chip and different concentration of adrenodoxine reductase (ADR): $0.1 \mu \mathrm{M}$ (1), $0.5 \mu \mathrm{M}$ (2), $1 \mu \mathrm{M}$ (3), $2.5 \mu \mathrm{M}(4), 5 \mu \mathrm{M}$ (5). Fitting curves (theoretical models) are highlighted in black; $\mathrm{Chi}^{2}$ values are equal to 10.5 and $0.5 \mathrm{RU}$ for association and dissociation phase, respectively. Complex dissociation constant $\left(\mathrm{K}_{\mathrm{d}}\right)$ values were calculated as ratio: $\mathrm{K}_{\mathrm{d}}=\mathrm{k}_{\mathrm{off}} / \mathrm{k}_{\mathrm{on}}$. (B) Binding levels of ferrochelatase $(\mathrm{FECH})$ or ADR used as analytes with immobilized monomer (dimer) form of FECH protein. All analytes were injected at a concentration of $5 \mu \mathrm{M}$ through biosensor channels for $10 \mathrm{~min}$ at a flow rate of $10 \mu \mathrm{L} / \mathrm{min}$. Data represent mean $\pm \mathrm{SD}, n=3$.

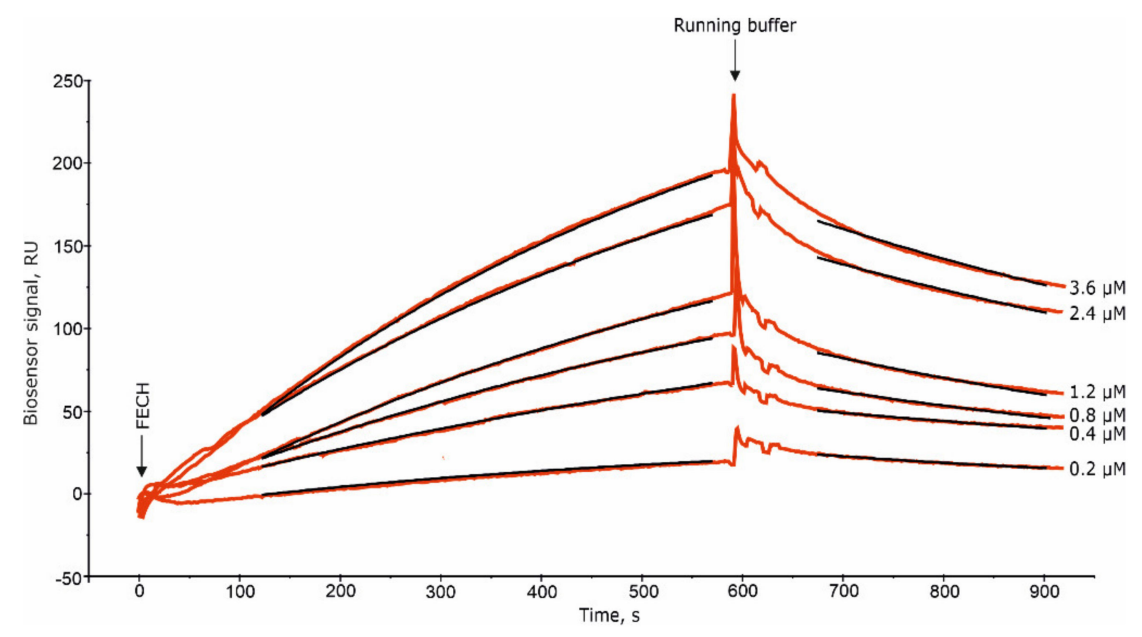

Figure 2. SPR analysis of ferrochelatase (FECH) dimerization. FECH solutions with different concentrations were injected through a biosensor channel with immobilized FECH monomers. Fitting curves (theoretical models) are highlighted in black; $\mathrm{Chi}^{2}$ values are equal to 0.3 and $1.0 \mathrm{RU}$ for association and dissociation phase, respectively. Complex dissociation constant $\left(\mathrm{K}_{\mathrm{d}}\right)$ values was calculated as ratio: $\mathrm{K}_{\mathrm{d}}=\mathrm{k}_{\mathrm{off}} / \mathrm{k}_{\mathrm{on}}$.

Experiments have shown that ADR interacted almost exclusively with the FECH monomers compared to dimers (Figure 1B).

It is especially important that ADR effectively interacted with its functionally significant protein partner adrenodoxin (Adx) (Figure S1). This suggests functional binding competence of ADR. The low level of ADR binding in the Fc4 channel with the FECH dimers could be explained by contaminations with FECH monomers in the channel. The presence of small amounts of monomers after the chemical stabilization of the dimeric form of other proteins was also noted earlier $[15,16]$. 


\subsection{The Effect of Isatin and Its Derivatives on FECH Interaction with Protein Partners}

In order to assess specificity of the isatin effect on PPI, we have investigated the effect of seven derivatives of isatin (Table 1), which differ in the key positions of the isatin molecule for the interaction with these proteins.

Table 1. The list of isatin derivatives which were used for the SPR analysis.

\begin{tabular}{|c|c|c|}
\hline Compound Number & Name/CAS/Empirical Formula/Molecular Weight, Da & Structure \\
\hline 0 & Isatin/91-56-5/ $\mathrm{C}_{8} \mathrm{H}_{5} \mathrm{NO}_{2} / 147$ & \\
\hline 1 & 5-Methylisatin/608-05-9/ $\mathrm{C}_{9} \mathrm{H}_{7} \mathrm{NO}_{2} / 161$ & \\
\hline 2 & 5-Bromoisatin/87-48-9/ $\mathrm{C}_{8} \mathrm{H}_{4} \mathrm{BrNO}_{2} / 226$ & \\
\hline 3 & 5-Iodoisatin/20780-76-1/C $\mathrm{C}_{8} \mathrm{H}_{4} \mathrm{INO}_{2} / 273$ & \\
\hline 4 & 5-Fluoroisatin/443-69-6/ $\mathrm{C}_{8} \mathrm{H}_{4} \mathrm{FNO}_{2} / 165$ & \\
\hline 5 & 5-Nitroisatin/611-09-6/ $\mathrm{C}_{8} \mathrm{H}_{4} \mathrm{~N}_{2} \mathrm{O}_{4} / 192$ & \\
\hline 6 & 5,7-Dichloroisatin/6374-92-1/ $\mathrm{C}_{8} \mathrm{H}_{3} \mathrm{Cl}_{2} \mathrm{NO}_{2} / 216$ & \\
\hline 7 & 3-hydroxy-3-(2-oxopropyl)indolin-2-one/ $\mathrm{C}_{11} \mathrm{H}_{11} \mathrm{NO}_{3} / 205$ & \\
\hline
\end{tabular}

In order to confirm our previous data [8], we have initially investigated the absence of significant interaction of these compounds individually with the monomeric form FECH and ADR immobilized on a chip. In these experiments two other proteins, B2M and BSA, were also used (Figure 3).

Figure 3 shows, that no noticeable binding of isatin (at the concentration achievable in vivo after administration of a pharmacologically relevant dose $[1,2,5]$ ) and its derivatives (except for 5-bromoisatin and 5-iodoisatin) was observed. For an additional "inverted" control, 5-aminoisatin was immobilized in one of the biosensor channels and samples of eight different recombinant proteins, including FECH and ADR, were injected. The binding signals of FECH and ADR to immobilized 5-aminoisatin slightly exceeded the binding range of the other six control proteins to 5-aminoisatin (Figure S2 and see 
also [17]). Next, a comparative SPR analysis of the possible effect of isatin derivatives on FECH homodimerization as well as FECH/ADR heterodimerization was performed, using the protocol described in our earlier work [8]. We did not find significant differences in the kinetic and affinity parameters of FECH/ADR and FECH/FECH complex formation in the presence of seven different isatin derivatives as compared to control (without isatin derivatives) (Table 2), whereas isatin induced complexation of FECH/ADR (Figure S3 and also [8]), but did not affect the formation of FECH/FECH dimers (Table 2). Although parameters of complex formation between FECH (cross-linked dimer) and ADR (Figure 1B) were not determined, but SPR protein binding signals in the presence of isatin remained unchanged. Thus, based on the data obtained, it can be assumed that the binding site of isatin in the FECH/ADR heterodimer is at the interface between two proteins and is not accessible for the binding of isatin derivatives used in this work. This result indicates the specificity of the action of isatin as a PPI regulator.

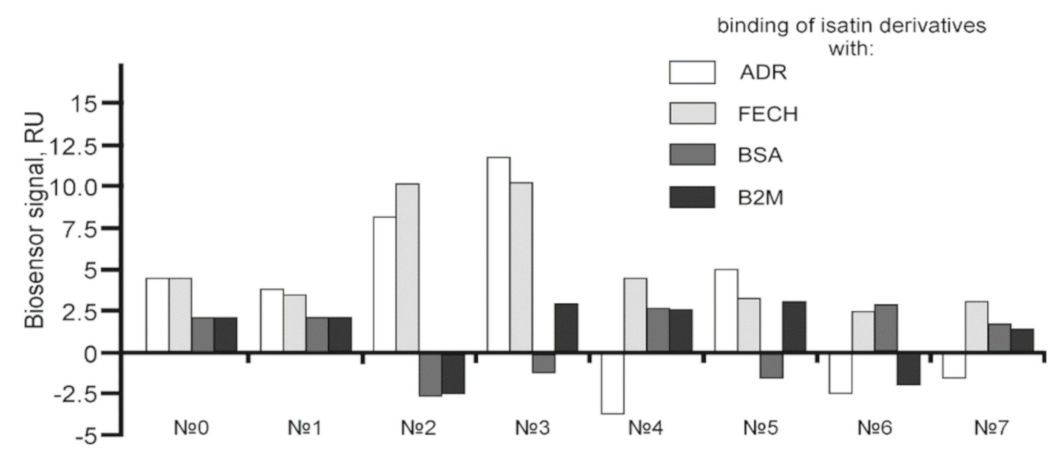

Figure 3. The average values of binding levels of isatin derivatives $(100 \mu \mathrm{M})$ with immobilized on the CM5 optical chip FECH monomer form, ADR, B2M and BSA $(n=3)$. FECH, ADR and control proteins B2M and BSA were immobilized up to $4000 \pm 200$ RU levels using the standard amino-coupling protocol. Isatin and its derivatives were dissolved in $96 \%$ ethanol. Isatin derivatives samples in HBS-EP+ buffer containing $1 \% v / v$ ethanol were injected for $10 \mathrm{~min}$ at a flow rate of $10 \mu \mathrm{L} / \mathrm{min}$. A solution containing $2 \mathrm{M} \mathrm{NaCl}$ and $0.4 \% \mathrm{CHAPS}$ was used for chip surface regeneration for $30 \mathrm{~s}$ at a flow rate of $25 \mu \mathrm{L} / \mathrm{min}$. The biosensor signals of compound binding above $5 \mathrm{RU}$ were considered to be significant (taking into consideration the baseline drift $0.5 \mathrm{RU} / \mathrm{min}$ after injection of the sample containing HBS-EP+ buffer with $1 \%$ ethanol). The numbers designate the following isatin derivatives tested: isatin (№0), 5-methylisatin (№1), 5-bromoisatin (№2), 5-Iodoisatin (№3), 5-fluoroisatin (№4), 5-nitroisatin (№5), 5,7-dichloroisatin (№6), 3-hydroxy-3-(2-oxopropyl)indolin-2-one (№7). Structures of these compounds are presented in Table 1.

Table 2. $\mathrm{K}_{\mathrm{d}}$ values $(\mu \mathrm{M})$ of FECH/ADR and FECH/FECH complex formation in the presence of $100 \mu \mathrm{M}$ isatin derivatives.

\begin{tabular}{|c|c|c|c|c|c|c|c|c|}
\hline Control * & №0 ** & №1 *** & №2 & №3 & №4 & №5 & №6 & №7 \\
\hline \multicolumn{9}{|c|}{ FECH/ADR } \\
\hline $15.2 \pm 1.2$ & $3.4 \pm 0.4$ & $14.3 \pm 1.2$ & $15.5 \pm 1.5$ & $14.1 \pm 0.8$ & $13.8 \pm 1.4$ & $13.7 \pm 0.9$ & $14.7 \pm 1.4$ & $15.5 \pm 0.8$ \\
\hline \multicolumn{9}{|c|}{ FECH/FECH } \\
\hline $0.55 \pm 0.11$ & $0.60 \pm 0.05$ & $0.57 \pm 0.06$ & $0.53 \pm 0.06$ & $0.54 \pm 0.05$ & $0.61 \pm 0.06$ & $0.56 \pm 0.08$ & $0.58 \pm 0.06$ & $0.53 \pm 0.10$ \\
\hline
\end{tabular}

\subsection{Molecular Modeling of the Isatin Effect on the Affinity of Protein-protein Interaction}

It was logical to assume that the affinity-enhancing effect of isatin on the pair of interacting proteins lacking individual isatin-binding sites (FECH and ADR) would involve the FECH/ADR heterodimer interface. In order to assess possibility of such scenario we performed computer modeling of possible configurations of molecular complexes formed. Figure 4 shows the algorithm of modelling. ClusPro, 
GRAMM-X, and ZDock. Among these programs ClusPro and ZDock present the values of scoring functions, while GRAMM-X presents a list of top 10 most probable complexes. Based on the scoring function of the ZDock output file (see Supplementary Materials, Tables S1 and S2), 10 top ZDock possible complexes were selected. Since the ClusPro program calculates several scoring functions, two sets of 10 models with the best "balanced" and "hydrophobic" scoring functions were selected (Table 3). Thus, 40 models of possible complexes (10 from GRAMM-X, 10 from ZDock, and 20 from ClusPro) were selected for the subsequent computer-aided analysis.

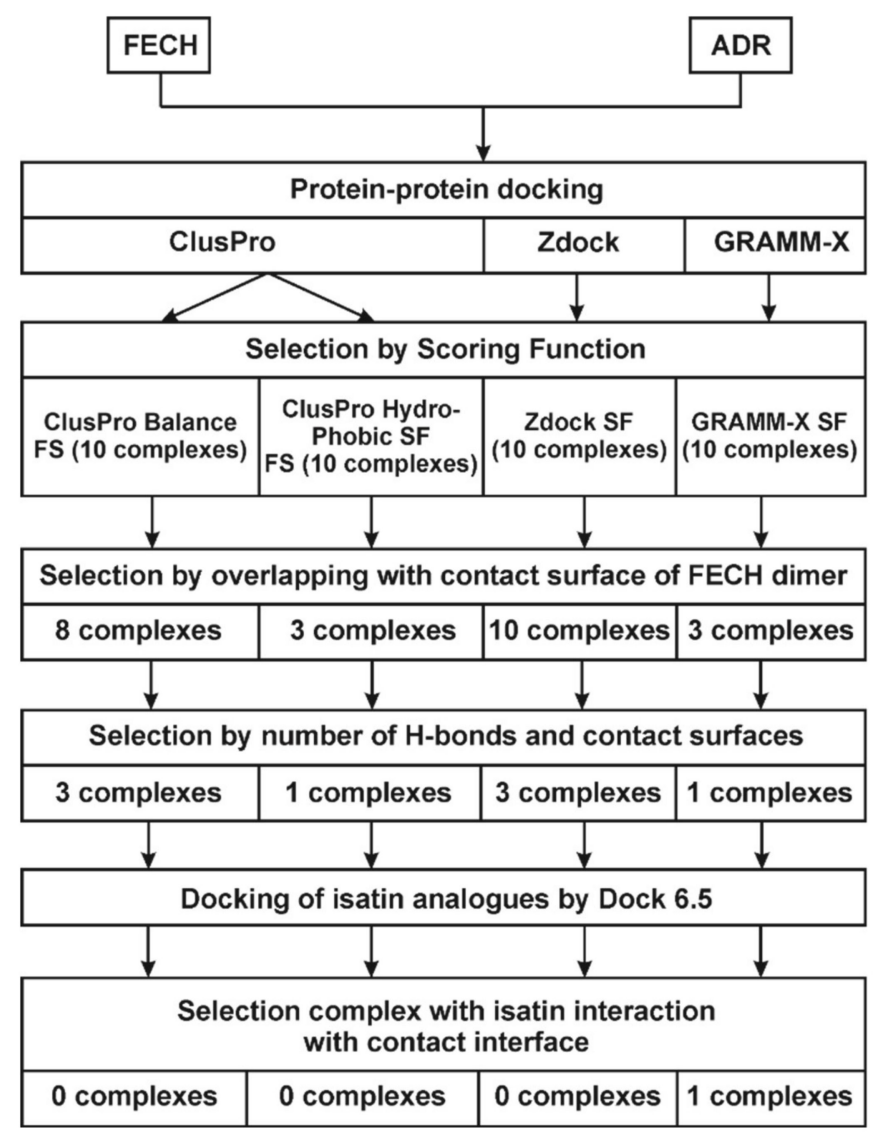

Figure 4. The algorithm of modeling of the FECH/ADR heterodimer complex with isatin.

Table 3. The values of the scoring function of ClusPro2.0 for models of the FECH/ADR heterodimer.

\begin{tabular}{cccc}
\hline N of Complex & Balanced Scoring Function & N of Complex & Hydrophobic Scoring Function \\
\hline 1 & -657.9 & 1 & -931.3 \\
2 & -705.0 & 2 & -910.8 \\
3 & -737.1 & 3 & -808.0 \\
4 & -680.9 & 4 & -986.8 \\
5 & -656.6 & 5 & $-815,3$ \\
6 & -672.8 & 6 & -922.9 \\
7 & -680.5 & 7 & -830.9 \\
8 & -740.7 & 8 & -914.8 \\
9 & $-742,9$ & 9 & -915.6 \\
10 & -673.6 & 10 & -882.2 \\
\hline
\end{tabular}

As shown above, the contact surface of FECH monomers is involved not only in the formation of homodimers (FECH/FECH) but also in formation of FECH/ADR heterodimers. Analysis of molecular models obtained using molecular docking showed that in 24 of 40 models of FECH/ADR complexes (ClusPro_balance-8, ClusPro_hydrophobic-3, GRAMM-X-3, ZDock-10) the interface of FECH in these 
complexes was overlapped with the interface in the FECH/FECH complex. For further selection of the most probable protein complexes, the contact areas of interacting proteins and the number of hydrogen bonds that could be formed between the interacting proteins were calculated. The contact area in the complexes varied from $673 \AA 2$ to $1412 \AA 2$, and the number of hydrogen bonds from 1 to 25 . Based on these data, 8 from 24 models of complexes were selected. These included ClusPro_balance-3, ClusPro_hydrophobic-1, GRAMM-X-1, ZDock-3 with contact areas ranged from $1056 \AA 2$ to $1412 \AA 2$ and the number of hydrogen bonds from 9 to 25 .

In order to find the most probable binding site involved in the isatin interaction with the FECH/ADR complex, molecular docking of isatin and its seven derivatives was performed over the entire surface of each of the 8 models of the complex. Data interpretation (and selection of the most appropriate model) was based on the SPR data (Figure 3) suggesting the lack of direct isatin interaction with the putative binding site.

Analysis of the results has shown that only one model satisfying all these criteria is possible: it includes the formation of the FECH/isatin/ADR ternary complex (Figure 5A). This model is based on one of the models obtained as a result of using the GRAMM-X program. In this ternary complex, isatin is located at the FECH contact interface with ADR and it interacts with both proteins with formation of two additional hydrogen bonds (one with each interacting protein). Other isatin derivatives do not bind at this site. It seems that additional substituents in compounds 2-7 have prevented their accommodation in the small cavity at the complex interface. Isatin interacts with the FECH residues THR229, GLN278, ALA282, GLN285 and LYS286 (and forms the H-bond) and also with ADR the residues ARG84 (forms the H-bond through oxygen of the main chain), ASP85 and ARG417 (Figure 5B). In the cell FECH/ADR heterodimers are obviously temporary complexes, which are formed during dissociation of the FECH dimer. Nevertheless, such complex formation may involve 13 hydrogen bonds and 10 salt bridges. The binding of increased concentrations of endogenous or exogenously administered isatin will stabilize these temporary complexes.

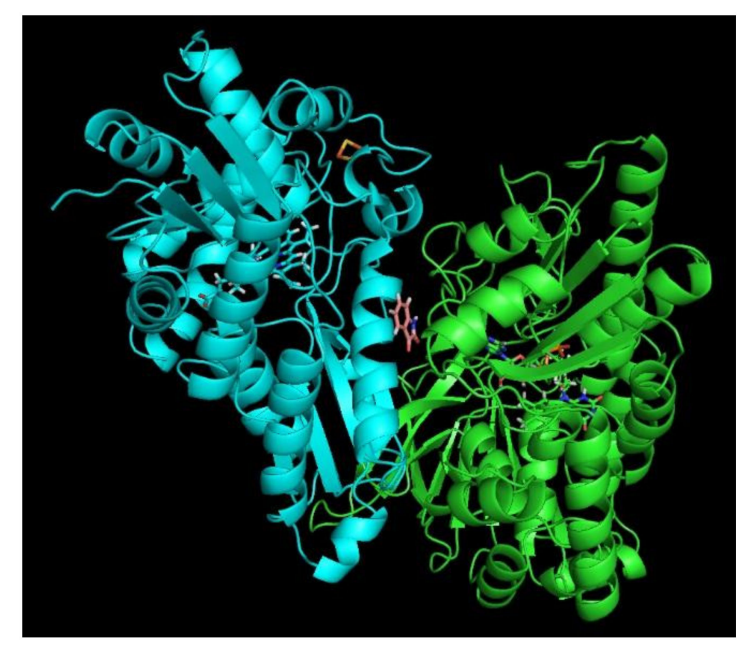

(A)

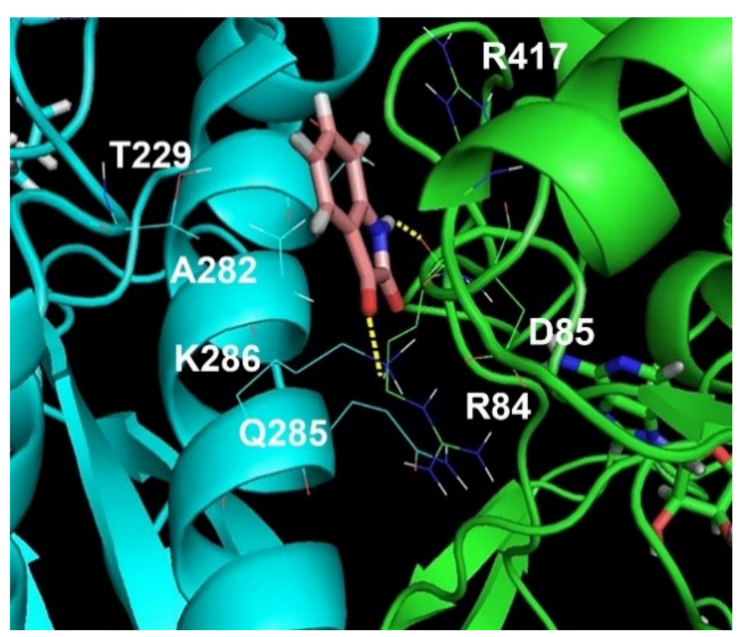

(B)

Figure 5. The model of a complex of FECH (cyan) and ADR (green) with isatin (A). Predicted isatin binding site in the FECH/ADR complex (B). Hydrogen bonds between isatin and amino acid residues of proteins are shown by a yellow dotted line. The model of complex was designed using FECH (PDB ID 2qd1, chain B) and ADR (PDB ID 1cjc, chain A).

\section{Discussion}

Using human FECH and ADR complex formation as a model system, in this study, we have considered a fundamentally new mechanism of the affinity-enhancing effect of isatin. 
This mechanism involves formation of a ternary complex protein/isatin/protein in which each of the interacting proteins does not bind isatin or binds it weakly. Isatin influenced only heterodimer formation by interacting with FECH and ADR monomers. At physiological concentrations isatin has no effect on such PPI. However, after administration of a pharmacologically relevant dose its intracellular level may significantly increase (such scenario has been considered in [1]). This suggests that at pharmacologically relevant concentrations this regulator will increase the affinity of some PPIs and thus change the interactome. Such mechanism provides reasonable explanation of the altered profile of isatin binding proteins observed after administration of a high neuroprotective dose of isatin to animals [18]: appearance of isatin-binding proteins specific for isatin-treated animals due to the formation of new clusters of PPI and/or novel ligand-induced binding sites.

According to the crystal structure, the adrenodoxin (ADX) complex formation with ADR, involves Asp79, Asp76, Asp72, and Asp39 of ADX and Arg211, Arg240, Arg244, and Lys27 residues of ADR, respectively [19]. The molecular binding site predicted in our studies by molecular modeling for isatin interaction with ADR is located outside the ADR binding region involved in the interaction with ADX, a canonical redox partner of mitochondrial cytochrome P450 (CYP).

It is known that FECH is involved in formation of various protein complexes with other proteins, for example, with frataxin [20] or with progesterone receptor membrane component 1 (PGRMC1) and PGRMC2 [21]. However, these interactions involve FECH surface sites other than the contact region responsible for interaction of FECH monomer with each other. In our experiments, in the absence of isatin, the low affinity FECH/ADR complex $\left(\mathrm{K}_{\mathrm{d}}\right.$ of about $\left.15 \mu \mathrm{M}\right)$ did not compete with the classical FECH/FECH dimerization $\left(\mathrm{K}_{\mathrm{d}}\right.$ of about $\left.0.5 \mu \mathrm{M}\right)$. However, in the presence of increasing isatin concentrations the equilibrium shifted towards formation of a higher affinity FECH/ADR complex $\left(\mathrm{K}_{\mathrm{d}} \leq 1 \mu \mathrm{M}\right)$ [8]. In this case, isatin can act as a molecular switch for the physiological reprogramming of the protein complex formation.

Although the functional importance of FECH/ADR heterodimerization remains unknown, certain evidence exists for indirect functional associations between FECH and ADR. For example, like $\mathrm{FECH}$, the protein pair ADR/ADX is also involved in the final stages of heme synthesis from protoporphyrin [22-25]. ADR acts as an electron carrier from NADPH to its redox partner, mitochondrial ferredoxin (adrenodoxin, ADX), thus participating in the reduction of $2 \mathrm{Fe}-2 \mathrm{~S}$ clusters [26]. In this context, it is possible that the presence of the 2Fe-2S cluster in FECH [11] determines interaction of this enzyme with ADR. Thus, the same intracellular localization of FECH and ADR [27,28], as well as ADR association with the functioning of enzymes containing $2 \mathrm{Fe}-2 \mathrm{~S}$ clusters $(\mathrm{FECH})$ may indicate that FECH and ADR are involved in the same biochemical pathway-the final stages of heme biosynthesis from protoporphyrin. These facts support the presence of a functional relationship between FECH and ADR, which may explain the fact of the intermolecular FECH/ADR interaction, which we found using an SPR biosensor. The biological role of the affinity-enhancing effect of isatin on FECH/ADR complex formation thus needs further investigation.

\section{Materials and Methods}

\subsection{Recombinant Proteins and Chemicals}

Highly purified preparations ( $>95 \%$ by SDS-PAGE) of human NADPH-dependent adrenodoxin reductase (ADR), mitochondrial cytochromes $b_{5}$ (CYB5B) were expressed and purified in the Institute of Bioorganic Chemistry NASB (Minsk, Belarus). Methods of their expression in E. coli cells as His-tagged proteins, their isolation, purification and functional analysis have been described earlier [29-31]. SMAD4 and FECH were expressed in E. coli as His-tagged proteins and purified to homogeneity by means of metal-affinity chromatography followed by chromatography on hydroxyapatite and dialysis [8]. Preparation of 5-aminoisatin was synthesized as described in [32]. The micrOTOF-Q II (Bruker, Bremen, Germany) mass-spectrometer was used for quality control of protein preparation according standard protocol of protein identification. Isatin derivatives were synthesized using standard 
chemical procedures in Far East Federal University (Vladivostok, Russia). Beta-2-microglobulin (B2M) and bovine serum protein (BSA) were purchased from USBio (Cat. No. M3890-17) (Salem, MA, USA) and Calbiochem (Lot 126609) (San Diego, CA, USA), respectively.

\subsection{Surface Plasmon Resonance (SPR) Analysis}

SPR analyses were carried out at $25^{\circ} \mathrm{C}$ using the optical biosensors Biacore T-200 and research grade sensor chips CM5 (GE Healthcare, Chicago, IL, USA). Optical biosensor Biacore 8K (GE Healthcare, Chicago, IL, USA) was also used for comparative assessment of binding of isatin and isatin derivatives with immobilized proteins on the optical chip surface. Running buffer HBS-EP+ $(150 \mathrm{mM} \mathrm{NaCl}, 3 \mathrm{mM}$ EDTA, 0.05\% Tween-20, 10 mM HEPES, pH 7.5) with $2 \mathrm{mM}$ dithiothreitol was used at a flow rate of 5 $\mu \mathrm{L} / \mathrm{min}$. The interaction of molecules was recorded as sensorgrams, representing the time-dependent change in biosensor signal in RU (resonance units, $1 \mathrm{RU}$ is equal to 1 pg material bound on chip surface). The values of rate constants $k_{\text {on }}$ and $k_{\text {off }}$ were calculated in the separate mode using the BIAevaluation 4.1 software (GE Healthcare, Chicago, IL, USA) and the Langmuir binding model (1:1 complex formation). Complex dissociation constant $\left(\mathrm{K}_{\mathrm{d}}\right)$ values were calculated as the ratio: $\mathrm{K}_{\mathrm{d}}=$ $\mathrm{k}_{\text {off }} / \mathrm{k}_{\text {on }}$. The SPR measurements were performed using the equipment of "Human Proteome" Core Facility of the Institute of Biomedical Chemistry (Moscow, Russia).

\subsubsection{FECH Immobilization on the SPR Chip}

FECH was used as an immobilized ligand; its covalent binding to the chip surface was performed in accordance with the standard covalent amino coupling protocol described in the Sensor surface handbook (GE Healthcare, Chicago, IL, USA). All immobilization steps were carried out at a flow rate of $5 \mu \mathrm{L} / \mathrm{min}$. After chip surface activation by injecting a mixture (1:1) of $50 \mu \mathrm{L}$ EDC and NHS $(25 \mu \mathrm{L}$ $400 \mathrm{mM}$ EDC and $25 \mu \mathrm{L} 100 \mathrm{mM}$ NHS) for $7 \mathrm{~min}$ the solution of FECH (50 $\mu \mathrm{g} / \mathrm{mL}$ in $10 \mathrm{mM}$ sodium acetate, $\mathrm{pH} 4.0$ ) was then injected into the activated flow cell. Unreacted groups on the CM5 chip surface were blocked with $1 \mathrm{M}$ ethanolamine- $\mathrm{HCl}(\mathrm{pH}$ 8.5). $\mathrm{FECH}$ was immobilized in flow channels Fc2, Fc3 and Fc4 at the level $2400 \pm 100$ RU. The blank signal from the FECH-free channel Fc1 (without the immobilized $\mathrm{FECH}$ ) was used for correcting non-specific binding of analytes to the dextran matrix of the chip. It was subtracted from the raw data, obtained from the flow cells Fc2, Fc3 and Fc4.

\subsubsection{Chemical Stabilization of FECH Dimers on the Optical Chip Surface}

Since FECH exists as a homodimer [10,11], its complex formation with ADR could be attributed to appearance of both ADR/FECH heterodimers and ADR/FECH/FECH heterotrimers. In order to clarify this point, we have carried out SPR experiments with immobilized monomers and stabilized dimers of FECH.

Dissociation of FECH dimer complexes was prevented by the method of chemical stabilization, which was previously successfully used in a number of studies for stabilization of various protein dimers on the surface of SPR chips $[15,16,33]$. The main steps for preparation of the model system of the FECH monomer-dimer on an optical biosensor chip are shown schematically in Table 4. After the immobilization of FECH in three channels of the biosensor ( $\mathrm{Fc} 2, \mathrm{Fc} 3$ and $\mathrm{Fc} 4$ ), the channels were washed with $5 \mathrm{mM} \mathrm{NaOH}$ for $15 \mathrm{~s}$ at a flow rate $25 \mu \mathrm{L} / \mathrm{min}$ for complete dissociation of protein complexes. This resulted in the decrease in the biosensor signal level in these channels from 2400 RU to $2200 \mathrm{RU}$. Subsequent experiments have shown that FECH immobilization with injections of various known reagents that destroy oligomeric complexes of proteins immobilized on a chip $(100 \mathrm{mM}$ mercaptoethanol; $4 \mathrm{M} \mathrm{NaCl} ; 0.12 \%$ SDS, $10 \mathrm{mM}$ glycine buffer, $\mathrm{pH}$ 1.5) the lack of the further decrease in the level of immobilized FECH. Thus, in the three working channels of the biosensor, the monomeric form of FECH was immobilized. In the Fc4 channel, the FECH dimers were formed by injecting the FECH solution $(5 \mu \mathrm{M})$ for 25 min (Figure S4). 
Table 4. Preparation of the model system "monomer-dimer" FECH on the chip of a four-channel SPR biosensor.

\begin{tabular}{ccccc}
\hline \multirow{2}{*}{ Biosensor Channel } & FECH Immobilization & \multicolumn{3}{c}{ Solution Injection } \\
\cline { 3 - 5 } & & $\mathbf{5} \mathbf{M M ~ N a O H}$ & FECH & NHS + EDC \\
\hline Fc1 (control 1) & + & - & - & - \\
FC2 (monomer form) & + & + & - & - \\
Fc3 (control 2) & + & + & - & + \\
Fc4 (dimer form) & + & + & + & + \\
\hline
\end{tabular}

Notes. Flow cell 1 (Fc1) is a control cell without any protein immobilization (control for nonspecific binding of analytes with dextran matrix); Fc2 is a cell with immobilized monomer form of FECH; Fc3 is a cell with immobilized monomer form of FECH stabilized by chemical cross-linking (additional control); Fc4 is a cell with rebuilt dimer form of FECH, stabilized by chemical cross-linking.

Immediately after protein immobilization, the NHS/EDC mixture $(10 \mu \mathrm{L} 400 \mathrm{mM}$ EDC and $10 \mu \mathrm{L}$ $100 \mathrm{mM} \mathrm{NHS}$ ) was injected for $2 \mathrm{~min}$. It is necessary for chemical stabilization of the FECH dimers by forming additional covalent bonds between the two FECH subunits in the dimers (Figure 6A), between adjacent dimers (Figure 6B), and/or between the FECH subunits and the dextran matrix (Figure 6C). After chemical stabilization, the rate of spontaneous FECH dimers dissociation decreased from about $20 \mathrm{RU} / \mathrm{min}$ to $<1 \mathrm{RU} / \mathrm{min}$. To control the absence of a negative effect of this procedure on the ability of $\mathrm{FECH}$ to interact with other proteins, we used the Fc3 channel with FECH monomers, through which the NHS/EDC mixture was also injected. After that, FECH solutions were injected through channels $\mathrm{Fc} 2$ and $\mathrm{Fc} 3$ in the concentration range $0.2-3.6 \mu \mathrm{M}$ (Figure 2). The set of obtained sensorgrams was used for calculation of $K_{d}$ values of FECH dimerization. The treatment with NHS/EDC insignificantly influenced the $K_{d}$ values (about $0.5 \pm 0.1 \mu \mathrm{M}$ ). Thus, for further studies, all four biosensor channels were used: "empty" channel Fc1 (control 1) to correct the results for possible non-specific sorption of analytes on a dextran matrix; channel Fc2 with immobilized FECH monomers; channel Fc3 with immobilized FECH monomers treated with a mixture of NHS/EDC (control 2); channel Fc4 with immobilized chemically stabilized FECH dimers.

\subsubsection{The SPR Study of Protein-Protein Interactions (PPIs)}

Solutions of FECH partner proteins (CYB5B, SMAD4, ADR) and FECH itself (concentration $5 \mu \mathrm{M}$ ) were injected (as analytes) through biosensor channels for $10 \mathrm{~min}$ at a flow rate of $10 \mu \mathrm{L} / \mathrm{min}$. For this, the biosensor mode "1-2-3-4 Quickinject" was used. The control signal from the "empty channel" FC1 (without immobilized protein) was subtracted from signals, obtained from other flow channels with the immobilized FECH in monomeric and dimeric forms. Solution containing $2 \mathrm{M} \mathrm{NaCl}$ and $0.4 \%$ CHAPS was used for the regeneration of the chip surface by injection for $30 \mathrm{~s}$ at a flow rate of 50 $\mu \mathrm{L} / \mathrm{min}$. All the experiments were executed at least three times. 


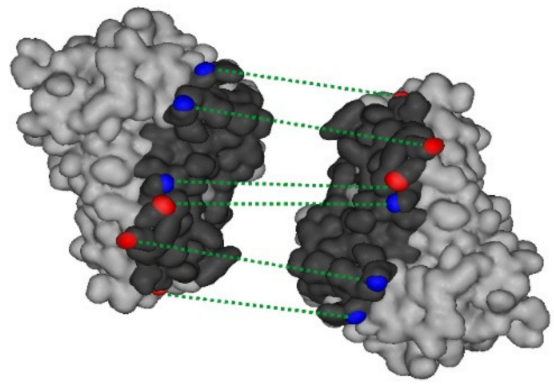

(A)

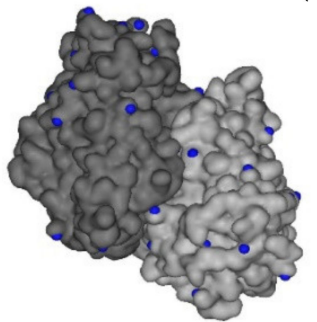

Front

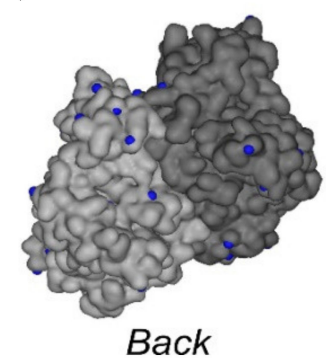

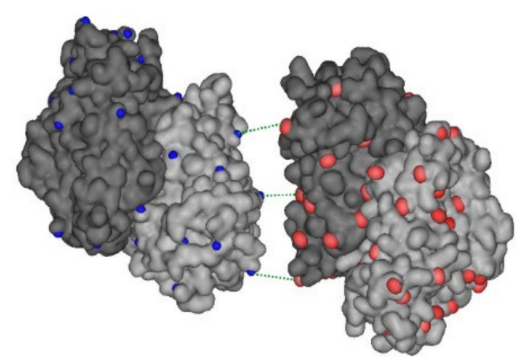

(B)

(C)

Figure 6. Visualization of 3D structure of ferrochelatase (FECH) protein (PDB ID 1HRK) with surface accessible chemical groups which can be critical for cross-linking between carboxyl groups of chip dextrane matrix and for intersubunit cross-linking. Surface lysine amino groups and carboxyl groups of ferrochelatase subunits are stressed with blue dots and red dots, respectively. Visualization was carried out using ViewerLite 5.0 software (Accelrys Inc., San Diego, CA, USA). (A) stabilization of FECH dimer via chemical cross-links between monomers in positions GLU255-LYS415, GLU292_LYS397, GLU289-LYS286, LYS286-GLU289, LYS397-GLU292 and LYS415-GLU255 is shown in dotted lines. The contact area of the monomers involved in the formation of a ferrochelatase homodimer is highlighted in dark gray. (B) two FECH dimer complexes with highlighted probable chemical cross-links "back to back" via amino groups of LYS (in positions 66, 106, 113, 133, 138, 145, 216, 243, $252,320,358,379,397$ ) and carboxyl groups of GLU (in positions 80, 141, 149, 176, 251, 292, 359, 369, 413) and ASP (in positions 87, 246, 369, 383). In the current example, formation of three cross-links (LYS243-GLU149, LYS138-GLU369, LYS66-GLU251) is shown in dotted lines. The FECH monomer A is shown in light gray and the monomer B in dark gray color. (C) front and back view of the FECH dimer with marked lysine amino groups in positions $66,106,113,133,138,145,216,243,252,320$, 358, 379,397 (for each subunits), which can form cross-linking with carboxyl groups of chip dextran matrix.

\subsection{Computer Aided Molecular Modeling and Docking}

The spatial structure of FECH (PDB ID 2qd1, chain B) and ADR (PDB ID 1cjc, chain A) were obtained from the RCSB Protein Data Bank (http://rcsb.org). The protein structures were optimized by Powell minimization using a Tripos force field in vacuum. The partial atomic charges on the proteins were calculated by Gasteiger-Huckel method. The structure of isatin was designed using Sybyl 8.1 software. The partial atomic charges of it was calculated by semiempirical AM1 methods using MOPAC 6.0. Protein-protein docking was performed using ClusPro [34], GRAMM-X [35] иZDock [36] programs. Docking parameters were used as default. Forty variants of protein-protein complexes from these programs were selected for further analysis. Molecular docking of isatin to complexes FECH/ADR was performed using the DOCK 6.5 program [37]. The solvent-accessible surface of the target for docking was built based on the Connolly algorithm with a probe radius of 1.4 $\AA$. The electrostatic and van der Waals potential fields generated over the target was calculated using a grid (spacing $0.3 \AA$ ); the non-bonded distance cutoff was $12 \AA$; the parameters for the van der Waals 
interactions were used from the dw_AMBER_parm99.defn set. The compounds were docked using a grid-based energy scoring option for minimization after their initial placement; the best docking pose was selected based on a scoring function from DOCK 6.5.

Supplementary Materials: The following are available online at http://www.mdpi.com/1422-0067/21/20/7605/s1.

Author Contributions: Conceptualization, P.V.E., A.E.M. and A.S.I.; Methodology, P.V.E., A.V.V. and Y.V.M.; Software, A.V.V.; Formal Analysis, P.V.E., A.V.V. and Y.V.M.; Investigation, P.V.E., Y.V.M. and A.V.V.; Resources, A.M.T., A.A.K., A.A.G. and T.V.M.; Data Curation, P.V.E., E.O.Y. and L.A.K.; Writing-Original Draft Preparation, P.V.E.; Writing-Review and Editing, P.V.E., Y.V.M., E.O.Y., L.A.K., A.E.M. and A.S.I.; Visualization, P.V.E., Y.V.M. and A.V.V.; Supervision, A.E.M. and A.S.I.; Project Administration, A.S.I. All authors have read and agreed to the published version of the manuscript.

Funding: This research was funded by the Program of Basic Scientific Research of National Science Academies for 2013-2020 and was performed using the equipment of "Human Proteome" Core Facility of the Institute of Biomedical Chemistry. Biosensor $8 \mathrm{~K}$ analysis and mass spectrometry quality control of protein preparation were funded by MINOBRNAUKI, Agreement № 075-15-2019-1502 from 5 September 2019.

Acknowledgments: The authors are grateful to Valentin A. Stonik (from Pacific Institute of Bioorganic Chemistry, Vladivostok, Russia) for his interest and valuable discussion.

Conflicts of Interest: The authors declare no conflict of interest.

\section{Abbreviations}

$\begin{array}{ll}\text { SPR } & \text { surface plasmon resonance } \\ \text { FECH } & \text { ferrochelatase } \\ \text { ADR } & \text { adrenodoxine reductase } \\ \text { PPI } & \text { protein-protein interactions } \\ \text { CYB5B } & \text { cytochrome b5 type B } \\ \text { SMAD4 } & \text { SMAD family member } 4 \\ \text { B2M } & \text { beta-2-microglobulin } \\ \text { BSA } & \text { bovine serum protein }\end{array}$

\section{References}

1. Medvedev, A.; Buneeva, O.; Gnedenko, O.; Ershov, P.; Ivanov, A. Isatin, an endogenous nonpeptide biofactor: A review of its molecular targets, mechanisms of actions, and their biomedical implications. BioFactors 2018, 44, 95-108. [CrossRef] [PubMed]

2. Medvedev, A.; Buneeva, O.; Glover, V. Biological targets for isatin and its analogues: Implications for therapy. Biologics 2007, 1, 151-162. [PubMed]

3. Buneeva, O.; Gnedenko, O.; Zgoda, V.; Kopylov, A.; Glover, V.; Ivanov, A.; Medvedev, A.; Archakov, A. Isatin-binding proteins of rat and mouse brain: Proteomic identification and optical biosensor validation. Proteomics 2010, 10, 23-37. [CrossRef] [PubMed]

4. Medvedev, A.E.; Buneeva, O.A.; Kopylov, A.T.; Gnedenko, O.V.; Medvedeva, M.V.; Kozin, S.A.; Ivanov, A.S.; Zgoda, V.G.; Makarov, A.A. The effects of endogenous non-peptide molecule isatin and hydrogen peroxide on proteomic profiling of rat brain amyloid- $\beta$ binding proteins: Relevance to Alzheimer's disease? Int. J. Mol. Sci. 2014, 16, 476-495. [CrossRef]

5. Crumeyrolle-Arias, M.; Buneeva, O.; Zgoda, V.; Kopylov, A.; Cardona, A.; Tournaire, M.-C.; Pozdnev, V.; Glover, V.; Medvedev, A. Isatin binding proteins in rat brain: In situ imaging, quantitative characterization of specific [3H]isatin binding, and proteomic profiling. J. Neurosci. Res. 2009, 87, 2763-2772. [CrossRef]

6. Buneeva, O.A.; Gnedenko, O.V.; Medvedeva, M.V.; Ivanov, A.S.; Medvedev, A.E. Oxidative modification of glyceraldehyde-3-phosphate dehydrogenase influences its interaction with endogenous neuroprotector isatin. Biochem. Mosc. Suppl. Ser. B 2015, 9, 185-188. [CrossRef]

7. Medvedev, A.; Buneeva, O.; Gnedenko, O.; Fedchenko, V.; Medvedeva, M.; Ivanov, Y.; Glover, V.; Sandler, M. Isatin interaction with glyceraldehyde-3-phosphate dehydrogenase, a putative target of neuroprotective drugs: Partial agonism with deprenyl. J. Neural Transm. 2006, (Suppl. 71), 97-103. [CrossRef] 
8. Ershov, P.; Mezentsev, Y.; Gilep, A.; Usanov, S.; Buneeva, O.; Medvedev, A.; Ivanov, A. Isatin-induced increase in the affinity of human ferrochelatase and adrenodoxin reductase interaction. Protein Sci. 2017, 26, 2458-2462. [CrossRef]

9. Svirid, A.V.; Ershov, P.V.; Yablokov, E.O.; Kaluzhskiy, L.A.; Mezentsev, Y.V.; Florinskaya, A.V.; Sushko, T.A.; Strushkevich, N.V.; Gilep, A.A.; Usanov, S.A.; et al. Direct Molecular Fishing of New Protein Partners for Human Thromboxane Synthase. Acta Nat. 2017, 9, 92-100. [CrossRef]

10. Burden, A.E.; Wu, C.; Dailey, T.A.; Busch, J.L.; Dhawan, I.K.; Rose, J.P.; Wang, B.; Dailey, H.A. Human ferrochelatase: Crystallization, characterization of the [2Fe-2S] cluster and determination that the enzyme is a homodimer. Biochim. Biophys. Acta 1999, 1435, 191-197. [CrossRef]

11. Wu, C.K.; Dailey, H.A.; Rose, J.P.; Burden, A.; Sellers, V.M.; Wang, B.C. The 2.0 A structure of human ferrochelatase, the terminal enzyme of heme biosynthesis. Nat. Struct. Biol. 2001, 8, 156-160. [CrossRef] [PubMed]

12. Ivanov, A.S.; Medvedev, A.; Ershov, P.; Molnar, A.; Mezentsev, Y.; Yablokov, E.; Kaluzhsky, L.; Gnedenko, O.; Buneeva, O.; Haidukevich, I.; et al. Protein interactomics based on direct molecular fishing on paramagnetic particles: Practical realization and further SPR validation. Proteomics 2014, 14, 2261-2274. [CrossRef] [PubMed]

13. Ivanov, A.S.; Ershov, P.V.; Molnar, A.A.; Yu, M.; Kaluzhskiy, L.A.; Yablokov, E.O.; Florinskaya, A.V.; Gnedenko, O.V.; Medvedev, A.E.; Kozin, S.A.; et al. Direct molecular fishing in molecular partners investigation in protein-protein and protein-peptide interactions. Russ. J. Bioorganic Chem. 2016, 42, 14-21. [CrossRef]

14. Ivanov, A.S.; Medvedev, A.E.; Buneeva, O.A.; Gnedenko, O.V.; Ershov, P.V.; Mezentsev, Y.V.; Yablokov, E.O.; Kaluzhskiy, L.A.; Florinskaya, A.V.; Moskaleva, N.E.; et al. The influence of gravity discharge on the content of isatin-binding proteins in mice: The results of ground-based and space research under the program BION-M no. 1. Biochem. (Mosc.) Suppl. Ser. B. Biomed. Chem. 2016, 10, 227-229. [CrossRef]

15. Ershov, P.V.; Gnedenko, O.V.; Molnar, A.A.; Lisitsa, A.V.; Ivanov, A.S.; Archakov, A.I. Biosensor analysis of the interaction of potential dimerization inhibitors with HIV-1 protease. Biochem. Mosc. Suppl. Ser. B. 2009, 3, 272-288. [CrossRef]

16. Ershov, P.V.; Gnedenko, O.V.; Molnar, A.A.; Lisitsa, A.V.; Ivanov, A.S.; Archakov, A.I. Kinetic and thermodynamic analysis of dimerization inhibitors binding to HIV protease monomers by surface plasmon resonance. Biochem. Mosc. Suppl. Ser. B. 2012, 6, 94-97. [CrossRef]

17. Ershov, P.V.; Mezentsev, Y.V.; Yablokov, E.O.; Kaluzhskiy, L.A.; Florinskaya, A.V.; Svirid, A.V.; Gilep, A.A.; Usanov, S.A.; Medvedev, A.E.; Ivanov, A.S. Specificity of Isatin Interaction with Cytochromes P450. Biochem. (Mosc.) Suppl. Ser. B: Biomed. Chem. 2018, 12, 130-135. [CrossRef]

18. Medvedev, A.; Kopylov, A.; Buneeva, O.; Kurbatov, L.; Tikhonova, O.; Ivanov, A.; Zgoda, V. A Neuroprotective Dose of Isatin Causes Multilevel Changes Involving the Brain Proteome: Prospects for Further Research. Int. J. Mol. Sci. 2020, 21, 4187. [CrossRef]

19. Müller, J.J.; Lapko, A.; Bourenkov, G.; Ruckpaul, K.; Heinemann, U. Adrenodoxin reductase-adrenodoxin complex structure suggests electron transfer path in steroid biosynthesis. J. Biol. Chem. 2001, 276, 2786-2789. [CrossRef]

20. Söderberg, C.; Gillam, M.E.; Ahlgren, E.-C.; Hunter, G.A.; Gakh, O.; Isaya, G.; Ferreira, G.C.; Al-Karadaghi, S. The Structure of the Complex between Yeast Frataxin and Ferrochelatase: Characterization and Pre-Steady State Reaction of Ferrous Iron Delivery and Heme Synthesis. J. Biol. Chem. 2016, 291, 11887-11898. [CrossRef]

21. Piel, R.B.; Shiferaw, M.T.; Vashisht, A.A.; Marcero, J.R.; Praissman, J.L.; Phillips, J.D.; Wohlschlegel, J.A.; Medlock, A.E. A Novel Role for Progesterone Receptor Membrane Component 1 (PGRMC1): A Partner and Regulator of Ferrochelatase. Biochemistry 2016, 55, 5204-5217. [CrossRef] [PubMed]

22. Fan, T.; Grimm, B.; Layer, G. Chapter Four-Porphyrin and heme synthesis. Metabolism, Structure and Function of Plant Tetrapyrroles: Control Mechanisms of Chlorophyll Biosynthesis and Analysis of Chlorophyll-Binding Proteins. In Advances in Botanical Research, Grimm, B., Ed.; Academic Press: Cambridge, MA, USA, 2019; Volume 91, pp. 89-131.

23. Shi, Y.; Ghosh, M.; Kovtunovych, G.; Crooks, D.R.; Rouault, T.A. Both human ferredoxins 1 and 2 and ferredoxin reductase are important for iron-sulfur cluster biogenesis. Biochim. Et Biophys. Acta Mol. Cell Res. 2012, 1823, 484-492. [CrossRef] [PubMed] 
24. Napoli, E.; Morin, D.; Bernhardt, R.; Buckpitt, A.; Cortopassi, G. Hemin rescues adrenodoxin, heme a and cytochrome oxidase activity in frataxin-deficient oligodendroglioma cells. Biochim. Biophys. Acta Mol. Basis Dis. 2007, 1772, 773-780. [CrossRef]

25. Ferreira, G.C.; Franco, R.; Lloyd, S.G.; Moura, I.; Moura, J.J.; Huynh, B.H. Structure and function of ferrochelatase. J. Bioenerg. Biomembr. 1995, 27, 221-229. [CrossRef]

26. Hurley, J.K.; Weber-Main, A.M.; Hodges, A.E.; Stankovich, M.T.; Benning, M.M.; Holden, H.M.; Cheng, H.; Xia, B.; Markley, J.L.; Genzor, C.; et al. Iron-sulfur cluster cysteine-to-serine mutants of Anabaena -2Fe-2Sferredoxin exhibit unexpected redox properties and are competent in electron transfer to ferredoxin:NADP+ reductase. Biochemistry 1997, 36, 15109-15117. [CrossRef] [PubMed]

27. Mitani, F.; Ishimura, Y.; Izumi, S.; Watanabe, K. Immunohistochemical localization of adrenodoxin and adrenodoxin reductase in bovine adrenal cortex. Acta Endocrinol. 1979, 90, 317-327. [CrossRef]

28. Sakaino, M.; Ishigaki, M.; Ohgari, Y.; Kitajima, S.; Masaki, R.; Yamamoto, A.; Taketani, S. Dual mitochondrial localization and different roles of the reversible reaction of mammalian ferrochelatase. FEBS J. 2009, 276, 5559-5570. [CrossRef]

29. Sergeev, G.V.; Gilep, A.A.; Usanov, S.A. The role of cytochrome b5 structural domains in interaction with cytochromes P450. Biochem. Mosc. 2014, 79, 406-416. [CrossRef]

30. Gilep, A.A.; Guryev, O.L.; Usanov, S.A.; Estabrook, R.W. Apo-cytochrome b5 as an indicator of changes in heme accessability: Preliminary studies with cytochrome P450 3A4. J. Inorg. Biochem. 2001, 87, 237-244. [CrossRef]

31. Usanov, S.A.; Graham, S.E.; Lepesheva, G.I.; Azeva, T.N.; Strushkevich, N.V.; Gilep, A.A.; Estabrook, R.W.; Peterson, J.A. Probing the Interaction of Bovine Cytochrome P450scc (CYP11A1) with Adrenodoxin: Evaluating Site-Directed Mutations by Molecular Modeling. Biochemistry 2002, 41, 8310-8320. [CrossRef]

32. Medvedev, A.E.; Goodwin, B.L.; Sandler, M.; Glover, V. Efficacy of isatin analogues as antagonists of rat brain and heart atrial natriuretic peptide receptors coupled to particulate guanylyl cyclase. Biochem. Pharmacol. 1999, 57, 913-915. [CrossRef]

33. Markgren, P.O.; Hämäläinen, M.; Danielson, U.H. Screening of compounds interacting with HIV-1 proteinase using optical biosensor technology. Anal. Biochem. 1998, 265, 340-350. [CrossRef] [PubMed]

34. Vajda, S.; Yueh, C.; Beglov, D.; Bohnuud, T.; Mottarella, S.E.; Xia, B.; Hall, D.R.; Kozakov, D. New additions to the ClusPro server motivated by CAPRI. Proteins 2017, 85, 435-444. [CrossRef] [PubMed]

35. Tovchigrechko, A.; Vakser, I.A. GRAMM-X public web server for protein-protein docking. Nucleic Acids Res. 2006, 34, W310-W314. [CrossRef]

36. Pierce, B.G.; Wiehe, K.; Hwang, H.; Kim, B.-H.; Vreven, T.; Weng, Z. ZDOCK server: Interactive docking prediction of protein-protein complexes and symmetric multimers. Bioinformatics 2014, 30, 1771-1773. [CrossRef]

37. Allen, W.J.; Balius, T.E.; Mukherjee, S.; Brozell, S.R.; Moustakas, D.T.; Lang, P.T.; Case, D.A.; Kuntz, I.D.; Rizzo, R.C. DOCK 6: Impact of new features and current docking performance. J. Comput. Chem 2015, 36, 1132-1156. [CrossRef]

Publisher's Note: MDPI stays neutral with regard to jurisdictional claims in published maps and institutional affiliations.

(C) 2020 by the authors. Licensee MDPI, Basel, Switzerland. This article is an open access article distributed under the terms and conditions of the Creative Commons Attribution (CC BY) license (http://creativecommons.org/licenses/by/4.0/). 